\title{
Peroxisome proliferator-activated receptor $\gamma$ agonist suppresses mast cell maturation and induces apoptosis
}

\author{
YU ZHANG* ${ }^{*}$ XINQIAN LI ${ }^{*}$, SHENGJIAN FANG, ZHENGHUA ZHU, \\ MIN YAO, LIYUN YING, LIWEI ZHU, ZHAOXIN MA and WEIHUA WANG \\ Department of Otolaryngology-Head and Neck Surgery, Shanghai East Hospital, \\ Tongji University School of Medicine, Shanghai 200120, P.R. China
}

Received November 6, 2016; Accepted June 8, 2017

DOI: $10.3892 / \mathrm{mmr} .2017 .6802$

\begin{abstract}
Peroxisome proliferator-activated receptor gamma (PPAR $\gamma$ ), is important in the immunoregulation of the allergic response. Mast cells are the most important inflammatory cells in immediate hypersensitivity and allergic diseases. However, there is limited information regarding the effects of PPAR $\gamma$ on mast cell maturation. In the present study, mouse bone marrow-derived mast cells (BMMCs) were cultured in interleukin (IL)-3 and stem cell factor (SCF), in the presence or absence of the PPAR $\gamma$ agonist, pioglitazone (PIO). The expression levels of the tyrosine kinase receptor CD117 and the high affinity IgE receptor FceRI $\alpha$, were assessed by flow cytometry, cell viability was assessed by Alamar-Blue assay and histamine release was determined by measuring the activity of $\beta$-hexosaminidase. IL-3 and SCF are required for the development of mast cells in vitro. PIO dose-dependently inhibited the expression of CD117 and FceRI $\alpha$, and the maturation of BMMCs. Treatment with PIO additionally inhibited the formation of granules and reduced the expression of $\beta$-hexosaminidase. In addition, reverse transcription-polymerase chain reaction analysis revealed that BMMCs treated with PIO expressed a lower level of mast cell protease $(M C P)-6$ mRNA and PIO treatment enhanced the level of PPAR $\gamma$ mRNA. Furthermore, PIO induced mast cell progenitor apoptosis. PPAR $\gamma$ agonists may maintain mast cell
\end{abstract}

Correspondence to: Dr Weihua Wang or Dr Zhaoxin Ma, Department of Otolaryngology-Head and Neck Surgery, Shanghai East Hospital, Tongji University School of Medicine, 150 Jimo Road, Shanghai 200120, P.R. China

E-mail: whwangcn@tongji.edu.cn

E-mail: mzhx114@163.com

*Contributed equally

Abbreviations: BMMCs, bone marrow-derived mast cells; IL-3, interleukin-3; PPAR, peroxisome proliferator-activated receptor; PIO, pioglitazone; SCF, stem cell factor

Key words: peroxisome proliferator-activated receptor, nuclear receptor, pioglitazone, mast cell, cell differentiation, inflammation homeostasis by inhibiting maturation of their precursors. The inhibitory effects of PPAR $\gamma$ agonists include suppression of the activation of mast cells and a decrease in mast cell function in the inflammatory response. Therefore, PPAR $\gamma$ agonists may serve as effective anti-inflammatory reagents in the treatment of allergic reactions.

\section{Introduction}

Peroxisome proliferator-activated receptor gamma (PPAR $\gamma$ ) is a ligand-dependent nuclear receptor and plays a critical role in fat metabolism and insulin sensitivity (1). PPAR $\gamma$ is expressed in adipose tissues, kidney, stomach, heart, liver, spleen, and brain (2). Recently, PPAR $\gamma$ is best known for its role in inflammatory and immunological responses (2-4). Many inflammatory cells, such as lymphocytes, neutrophils, and macrophages, express PPAR $\gamma$, and are the potential targets of PPAR $\gamma$-mediated inhibitory functions (2). PPAR $\gamma$ agonists have been demonstrated as therapeutic agents in autoimmunity and allergic diseases $(2,3,5-7)$. In monocyte/macrophage system, the relationship between PPAR $\gamma$ activation and negative regulation of cytokines production has been demonstrated $(4,8,9)$. Other inflammatory cells, such as mast cells, may be potential targets of PPAR $\gamma$. Although previous studies reported that mast cells express PPAR $\gamma(9-11)$, it remains obscure how PPAR $\gamma$ signaling affects the nature of mast cells. The function and mechanism of PPAR $\gamma$ in mast cells should be studied further.

Mast cells play an important role in immediate hypersensitivity and allergic diseases via the cross-linking of IgE/high affinity $\operatorname{IgE}$ receptors (FcRIs) by multivalent allergens (12). The cross-linking results in degranulation, prostaglandin and leukotriene synthesis, and production of various cytokines and chemokines (13), which cause the early and late phase of allergic responses. Mast cells derive from bone marrow stem cells, subsequently flow into blood stream in the immature stage, and differentiate at the peripheral tissues. The growth, differentiation, maturation, and survival of mast cells in bone marrow and in various tissues are largely mediated by signals of kit receptor (CD117) and interleukin (IL)-3 receptor (14). After stimulation with stem cell factor (SCF, kit ligand) and IL-3, the immature mast cells differentiate into mature stage. PPAR $\gamma$ expression has been reported in bone marrow-derived 
mast cells (BMMCs), and PPAR $\gamma$ ligand administration can attenuate atopic and contact dermatitis in mice (2). PPAR $\gamma$ activation dramatically suppresses neural stem cell differentiate into maturate neurons (15). Thus, we speculate that the development and maturation of bone marrow progenitors might be regulated by PPAR $\gamma$ pathway.

Given the evidence of negative effects of PPAR $\gamma$ agonist on allergic diseases, we have sought to examine how PPAR $\gamma$ agonist affects mast cell development from bone marrow progenitors. Our findings indicate that PPAR $\gamma$ agonist reduces the phenotypic markers and viability of mast cells, inhibits degranulation, and induces cell apoptosis. These data suggest that PPAR $\gamma$ may be a regulator of mast cells response and a novel therapeutical strategy for treatment of mast cell-related diseases.

\section{Materials and methods}

Cell culture and reagents. Bone marrow cells were flushed and collected from the femurs and tibias of C57BL/6 J female mice (6-10 weeks old) (Shanghai SLAC laboratory Animal Co., Ltd., Shanghai, China) and cultured in complete RPMI (RPMI-1640; Corning Cellgro, Manassas, VA, USA) containing 10\% fetal bovine serum (FBS) (Gibco; Thermo Fisher Scientific, Waltham, MA, USA), 2 mM L-glutamine, $100 \mathrm{U} / \mathrm{ml}$ penicillin, $100 \mathrm{mg} / \mathrm{ml}$ streptomycin, $1 \mathrm{mM}$ sodium pyruvate, and $1 \mathrm{mM}$ HEPES, supplemented with IL-3 (10 ng/ml) and SCF (10 ng/ml) (both from Peprotech, Inc., Rocky Hill, NJ, USA), with or without pioglitazone (PIO, 0-20 $\mu \mathrm{M})$ (R\&D Systems, Inc., Minneapolis, MN, USA) or vehicle (DMSO). Cultures were incubated for the indicated times. Every 4 days, the nonadherent population was collected and half of the medium and cytokines were replaced. For system evaluation, mice were treated with or without PIO hydrochloride $(30 \mathrm{mg} / \mathrm{kg}$ body weight/d; Actos; Takeda Pharmaceuticals, Ltd., Osaka, Japan) by oral gavage for one week, and the bone marrow cells were harvested for further study.

Assessment of differentiation. BMMCs were harvested after 1-8 weeks and differentiation was monitored on a weekly basis. To detect the development of BMMCs, cells were washed and assessed for surface expression of CD117 and FceRI $\alpha$. Briefly, cells were stained with a combination of PE-conjugated anti-mouse CD117 and FITC-conjugated anti-mouse FceRI $\alpha$ (BioLegend, Inc., San Diego, CA, USA) for $30 \mathrm{~min}$ at $4^{\circ} \mathrm{C}$. Then, cells were washed and subjected to flow cytometry analysis (BD Biosciences, San Jose, CA, USA). Negative controls included isotype-matched conjugated, nonspecific antibodies (BioLegend, Inc.). Data were analyzed using the FlowJo software (version 7.5.1; FlowJo, LLC, Ashland, OR, USA).

Reverse transcripton-polymerase chain reaction analysis. Total RNA was extracted from BMMCs using Trizol reagent (Invitrogen, Carlsbad, CA, USA) according to the manufacturer's instructions. The first strand cDNA was reverse-transcribed from $1 \mu \mathrm{g}$ of total RNA by using oligo $(\mathrm{dT})_{12-18}$ primer (Takara Bio, Inc., Otsu, Japan). The reaction mixture was amplified with the oligonucleotides specific for mast cell protease (MCP)-6, PPAR $\gamma$, and $\beta$-actin using ABI 7500 Real-Time PCR System and SYBR-Green PCR master mix (Takara). Specific primer sequences are as follows: for MCP-6: sense 5'-CCACTGGTCTGCAAAGTGAA-3' and antisense 5'-CAGAGGACA AGGAAGGCAAG-3'; for PPAR $\gamma$ : sense 5'-TGACACAGAGATCGCATTCTGG-3' and antisense 5'- ACAGACACGACATTCAATTGCC-3'; for $\beta$-actin: sense 5'-CCCATCTACG AGGGCTAT-3' and antisense 5'-TGTCACGCACGATTTCC-3'.

Cell viability and characterization of BMMCs. BMMCs were starved by replacing complete medium with RPMI without serum and IL-3/SCF for $6 \mathrm{~h}$. Cells were seeded into 96-well plates at a density of $25 \times 10^{4} / \mathrm{ml}$ and stimulated with or without PIO in complete medium for $48 \mathrm{~h}$. The relative cell viability was determined using Alamar-Blue Cell Viability assay according to the manufacturer's instructions (BioSource, Camarillo, CA, USA). Briefly, at the end of incubation, each well was supplied with $10 \mu 1$ of AlamarBlue reagent. Plates were incubated at $37^{\circ} \mathrm{C}$ for $2 \mathrm{~h}$, and absorbance was measured at $490 \mathrm{~nm}$ with Omega microplate reader (Ingen Technologies, Inc., Alexandria, VA, USA).

BMMCs were harvested after 4 weeks and washed with PBS. Cells were centrifuged onto glass slides. Cells were fixed in Carnoy's solution. To investigate the maturation of mast cells, granules were stained with toluidine blue (Sigma-Aldrich, St. Louis, MO, USA) and photomicrographs were taken at a magnification of x400 using Leica Microsystems Inc. (Bannockburn, IL, USA).

Degranulation assay. The degranulation of BMMCs was detected by measuring the activity of a granular enzyme, $\beta$-hexosaminidase. After 4 weeks, BMMCs were sensitized with $100 \mathrm{ng} / \mathrm{ml}$ anti-DNP IgE overnight. The sensitized cells were stimulated with $100 \mathrm{ng} / \mathrm{ml}$ of DNP-BSA in Tyrode's buffer at $37^{\circ} \mathrm{C}$ for $30 \mathrm{~min}$, and the supernatant and pellet were collected. Release of $\beta$-hexosaminidase was evaluated using p-nitrophenyl-N-acetyl- $\beta$-D-glucosamine (Sigma-Aldrich). The percentage of $\beta$-hexosaminidase release was expressed as $100 \mathrm{x}$ supernatant activity/(supernatant activity + cell lysate activity) as described previously (16).

Apoptosis assay. Mast cells apoptosis was assessed by Annexin V assay. Briefly, BMMCs were washed once in $1 \mathrm{ml}$ of 1xAnnexin $\mathrm{V}$ binding buffer. The supernatants were removed by centrifugation and cells were suspended in 1xAnnexin V binding buffer. A $5 \mu 1$ of FITC-conjugated Annexin V (BD Biosciences) and $5 \mu \mathrm{l}$ of prodium iodide were added to the cells. Cells were mixed gently and incubated for $15 \mathrm{~min}$ at room temperature in the dark, and diluted with $400 \mu 1$ of 1xAnnexin $\mathrm{V}$ binding buffer. Data were analyzed by flow cytometry within $1 \mathrm{~h}$.

Statistical analysis. Results are expressed as mean \pm standard deviation (SD). Statistical analysis was performed by Student's t-test or ANOVA using SPSS Version 19 (IBM, Chicago, IL, USA). $\mathrm{P}<0.05$ was considered to indicate a statistically significant difference.

\section{Results}

Effects of IL-3 and SCF on development of mast cells cultured from bone marrow progenitors. To observe the 
A

Week 1

Week 4

Week 6
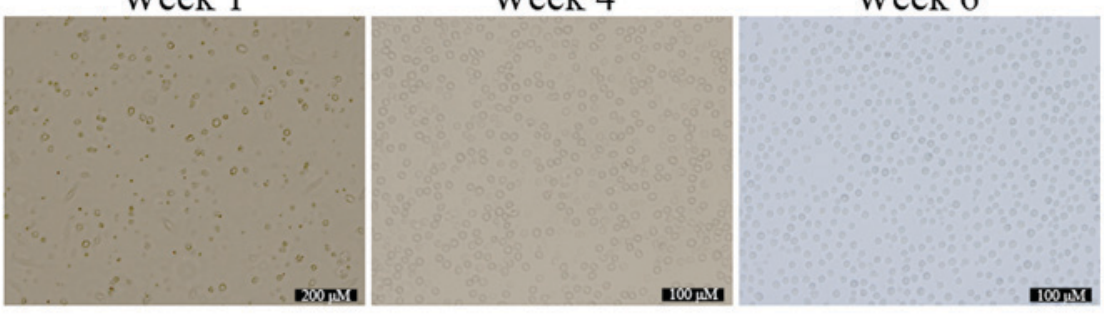

B
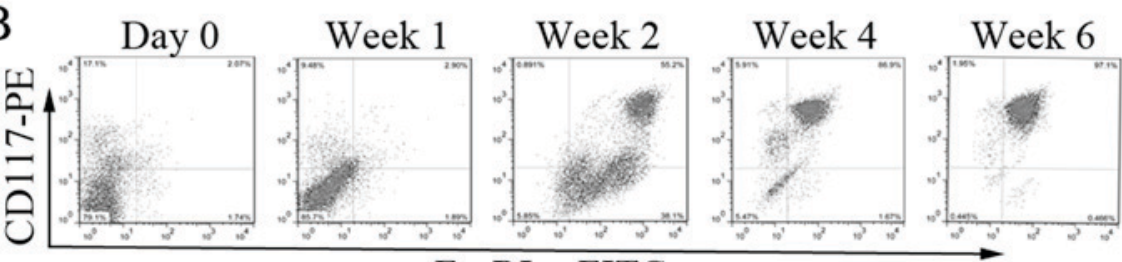

FceRI $\alpha$-FITC

Figure 1. Effect of IL-3 and SCF on development of BMMCs. (A) Characteristic of BMMCs cultured with IL-3 and SCF for 1, 4, and 6 weeks under light microscope. (B) Bone marrow cells were cultured with IL-3 and SCF for up to 6 weeks. Cells were harvested and stained with PE-conjugated anti-mouse CD117 and FITC-conjugated anti-mouse FceRI $\alpha$. Stained cells were subjected to flow cytometry analysis. Data shown are representative of three cultures. BMMCs, bone marrow-derived mast cells. BMMCs, bone marrow-derived mast cells; SCF, stem cell factor.

mature process of mast cells in vitro, bone marrow cells were cultured with different concentrations of IL-3 and SCF for up to 8 weeks. This system is widely used to study mast cells development, and yields cells closely resembling the in vivo counterparts (17). Since the driving effects of IL-3 and SCF on development of mast cells became more pronounced when the concentration was $10 \mathrm{ng} / \mathrm{ml}$, we conducted the subsequent experiments with $10 \mathrm{ng} / \mathrm{ml}$ for IL-3 and SCF. After 2 days of culture, adherent cells began to appear, and the cells were relatively single, short shuttle-like or round. Suspension cells varied widely in shape and size. With the extending of incubation time, the number of adherent cells was less and less, and the suspension cells number gradually increased. The form of suspension cells was uniform, round-shaped, and bright by the end of week 6 (Fig. 1A).

The expression of two specific mast cell markers, CD117 and FceRI $\alpha$, was investigated. Both positive cells are defined mature mast cells (2). The mean percentage of cells co-expressing CD117 and FceRI $\alpha$ in freshly isolated bone marrow progenitors was $2.13 \pm 0.56 \%(n=3)$. The maturation of BMMCs was significantly enhanced in cells receiving IL-3 and SCF with time. At the end of week 1, 2, 4, and 6, the percentage of CD117/FceRI $\alpha$ positive cells were $3.05 \pm 1.15 \%$, $52.67 \pm 3.45 \%, 87.43 \pm 4.87 \%$, and $98.16 \pm 3.97 \%$ respectively, $\mathrm{n}=3$ (Fig. 1B). When BMMCs were cultured for more than 8 weeks, the percentage of CD117/FceRI $\alpha$ positive cells decreased to about $60 \%$ (data not shown). These results indicate that bone marrow progenitors can be stably induced into mature mast cells in vitro in the presence of IL-3 and SCF.

PPAR $\gamma$ agonist inhibits cell-surface antigen expression on $B M M C$ s. PPAR $\gamma$ plays an important role on mast cells differentiation and is potentially useful for the therapy in allergic disorders $(2,3,7,9)$. To evaluate the effects of PPAR $\gamma$ agonist on mast cells development, we measured the expression of CD117/FceRI $\alpha$ after culture in IL-3 and SCF with different concentrations of PIO $(0,5$, and $20 \mu \mathrm{M})$. PIO treatment decreased cell surface expression of CD117 and FceRI $\alpha$ in a concentration-dependent manner, with significant reduction in surface antigens expression at $20 \mu \mathrm{M}$ (Fig. 2).

The percentage of cells co-expressing CD117 and FceRI $\alpha$ was consistently reduced by greater than $28 \%$ by week 2 and 3 with PIO at $20 \mu \mathrm{M}$. However, CD117 expression was more sensitive to the inhibitory effect of PIO than that of FceRI $\alpha$. Similar results were obtained at the end of week 4 and 6 . These results indicate that PPAR $\gamma$ agonist can decrease the expression of specific mast cell antigens and inhibit mast cells maturation.

PPAR $\gamma$ agonist suppresses mast cells viability and induces cell apoptosis. The inhibitory effects of PIO on BMMCs could be due to proapoptotic effect. To demonstrate the effects of PPAR $\gamma$ agonist on BMMCs, cell viability was determined by Alamar-Blue assay. After 4 weeks of culture, the percentage of mature BMMCs was increased to more than $85 \%$ (Fig. 1B). Before cell viability assay, cells were starved for $6 \mathrm{~h}$ in medium without FBS and cytokines. Then BMMCs were cultured in complete medium with IL-3 and SCF for a further 7 days, with or without PIO (5-20 $\mu \mathrm{M})$. In the presence of PIO, the total number of mast cells was decreased and the cell viability was inhibited in a dose-dependent manner (Fig. 3A). The viability of BMMCs cultured with PIO $(20 \mu \mathrm{M})$ was decreased to $50.4 \pm 7.71 \%(n=3)$. We hypothesized that PIO could induce BMMCs programmed death. Therefore, the effect of PIO on cell apoptosis was evaluated $48 \mathrm{~h}$ after incubation in the presence or absence of PIO $(20 \mu \mathrm{M})$. The percentage of Annexin $\mathrm{V}^{+} \mathrm{PI}^{+}$cells was $19.2 \pm 1.51 \%$ in PIO treated cultures, vs. $14.9 \pm 0.87 \%$ in control $(\mathrm{P}<0.05)(\mathrm{n}=3)$ (Fig. $3 \mathrm{~B})$.

PPAR $\gamma$ agonist inhibits mast cells granule formation and the release of $\beta$-hexosaminidase. The cross-linking of IgE/FceRI complexes by allergens has been shown to coincide with mast cells granulation $(13,18)$, and enhances the characteristic mast cells morphology. In the present study, PIO played a weak role 


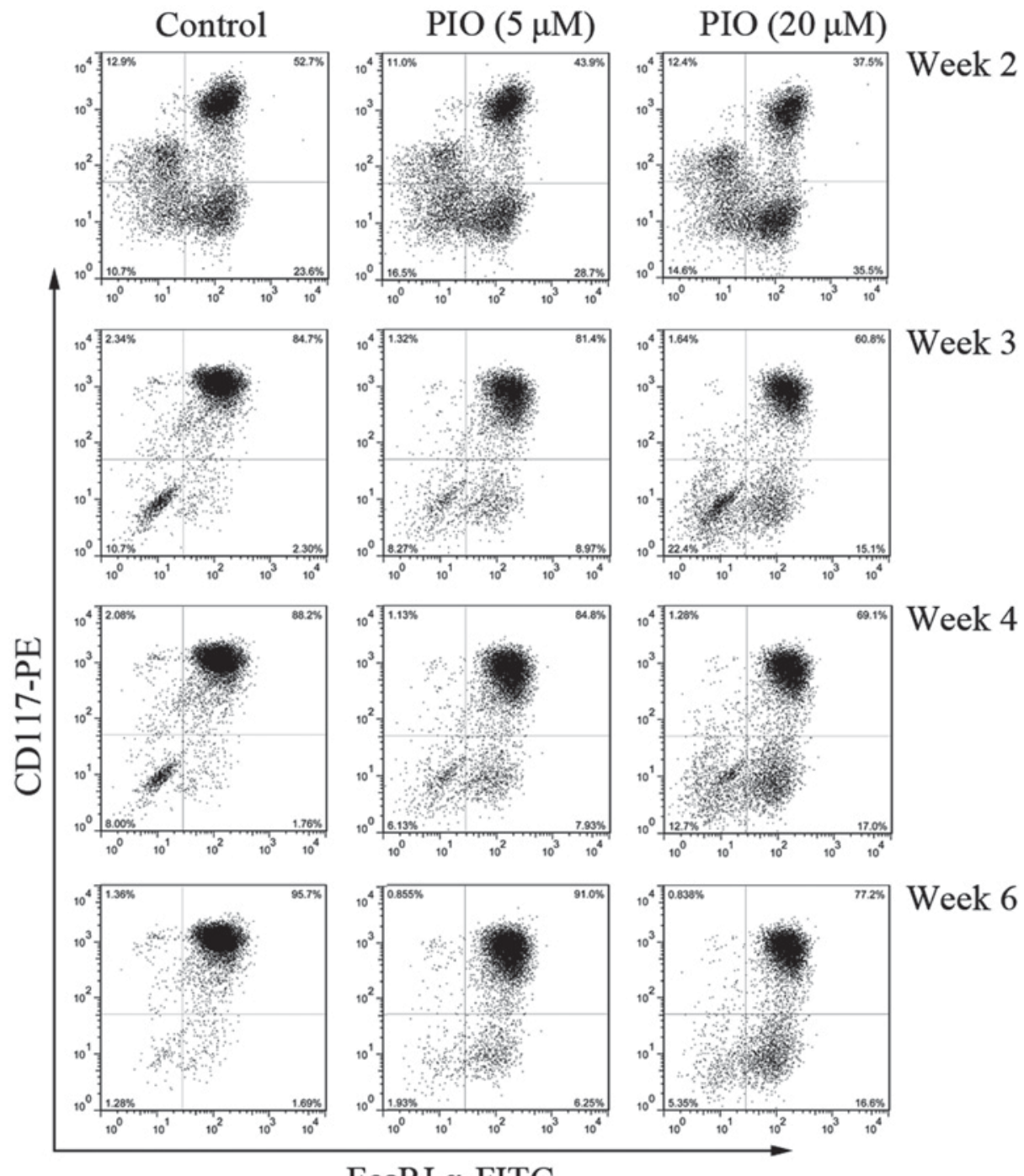

FceRI $\alpha$-FITC

Figure 2. PIO inhibits CD117 and FceRI $\alpha$ expression on BMMCs. Bone marrow cells were cultured in IL-3 and SCF with PIO at the indicated concentrations for 2-6 weeks. Expression of CD117 and FceRI $\alpha$ on the surface of BMMCs was analyzed by flow cytometry. The data is representative of three independent experiments. PIO, pioglitazone; BMMCs, bone marrow-derived mast cells.

in FceRI $\alpha$ expression, therefore we determined the effects of PIO on mast cells morphology. BMMCs cultured in IL-3 and SCF with PIO (5-20 $\mu \mathrm{M})$ for 4 weeks were centrifuged onto glass slides and stained with toluidine blue. The cells had a homogeneous appearance at either concentration of PIO. However, the treatment of PIO altered the appearance of cytoplasmic granules from these cells. While cells cultured with vehicle and PIO at $5 \mu \mathrm{M}$ showed prominent granule formation, $\mathrm{PIO}$ at $20 \mu \mathrm{M}$ greatly inhibited granule formation and resulted in empty vacuoles and swelling of granules (Fig. 4A). The functional effects of PIO on histamine synthesis and release were determined by measuring $\beta$-hexosaminidase activity. We found that the level of $\beta$-hexosaminidase release were reduced $25 \%$ by PIO administration at $20 \mu \mathrm{M}$ (Fig. 4B). These results indicate that PIO inhibits granule formation and function of mast cells.

PPAR $\gamma$ agonist alters the expression of MCP-6 and PPAR $\gamma$ mRNAs. It has been reported that MCP-6, a mature mast cells-specific tryptase, is a potent inflammatory mediator and is needed for the development of airway hyperresponsiveness $(19,20)$. To determine whether PPAR $\gamma$ activation affects mast cells maturation, we measured the expression levels of MCP-6 and PPAR $\gamma$ mRNA in BMMCs treated with PIO. $M C P-6$ mRNA expression level was significantly decreased in BMMCs treated with PIO for 4 weeks when compared with that of control cells. In contrast, PIO treatment induced a 3-fold increase in PPAR $\gamma$ mRNA expression in BMMCs (Fig. 5).

PPAR $\gamma$ agonist maintains the inhibitory effects on bone marrow cells in vitro. To determine the role of PPAR $\gamma$ agonist on BMMCs development after systemic administration, bone marrow cells from mice with or without oral gavage with PIO for 7 days were cultured for 3 weeks with IL-3 and SCF. As seen in Fig. 6, the percentage of CD117/FceRI $\alpha$ double-positive cells from PIO gavage mice is lower than that from control mice $(56 \pm 4.2 \%$ vs. $78 \pm 3.5 \%, \mathrm{P}<0.05, \mathrm{n}=3)$. These data indicate that mast cells development from PIO-treated mice is suppressed partially by PPAR $\gamma$ activation even in the culture condition without PIO. 
A
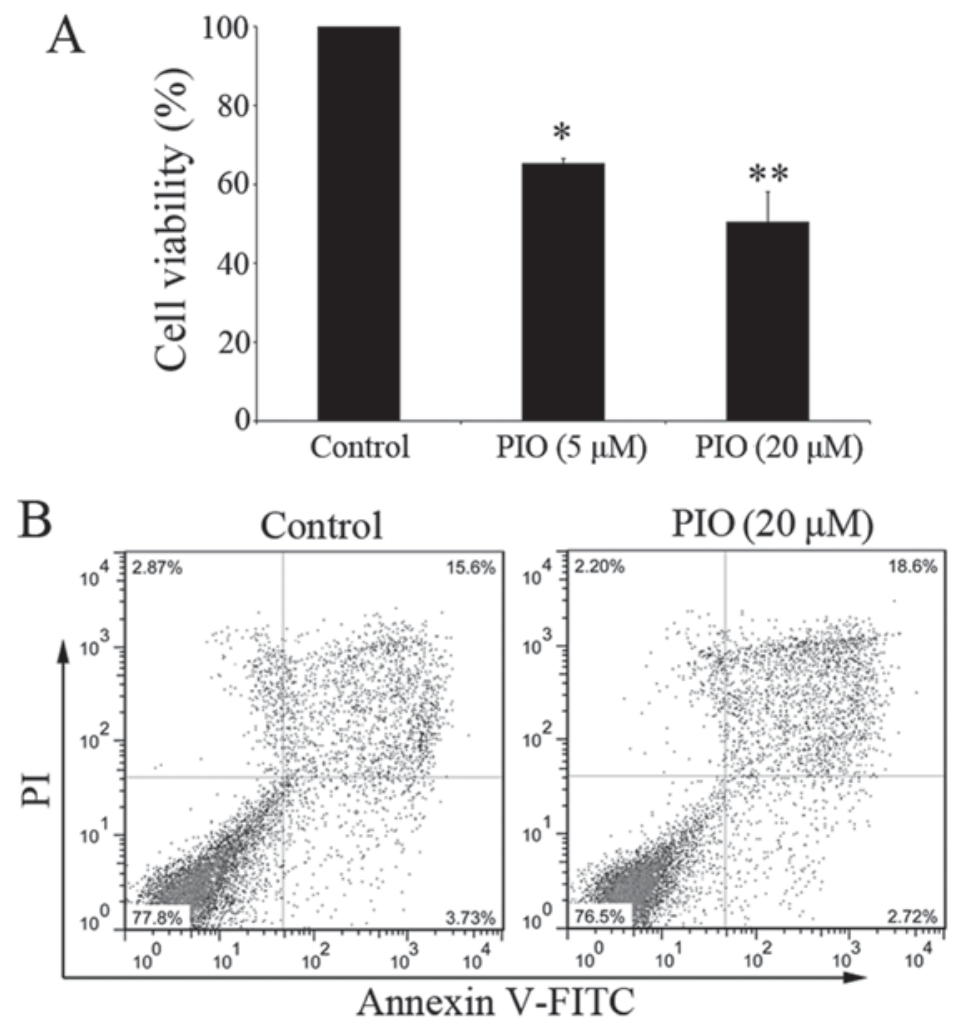

Figure 3. PIO inhibits mast cells proliferation and induces apoptosis. (A) After 4 weeks' culture, BMMCs were starved for 6 h. Cells were cultured in complete medium with IL-3 and SCF for 7 days in the presence of PIO. Cell viability was determined by Alamar-Blue assay. The viability of control cells was set at $100 \%$ and the viability relative to control is presented. ${ }^{*} \mathrm{P}<0.05$ vs. control, ${ }^{* *} \mathrm{P}<0.01$ vs. control. (B) BMMCs were cultured with or without PIO (20 $\left.\mu \mathrm{M}\right)$ for $48 \mathrm{~h}$. Cells were stained with Annexin V and PI and analyzed by flow cytometry. Data shown are representative of three independent experiments. PIO, pioglitazone; BMMCs, bone marrow-derived mast cells; SCF, stem cell factor.
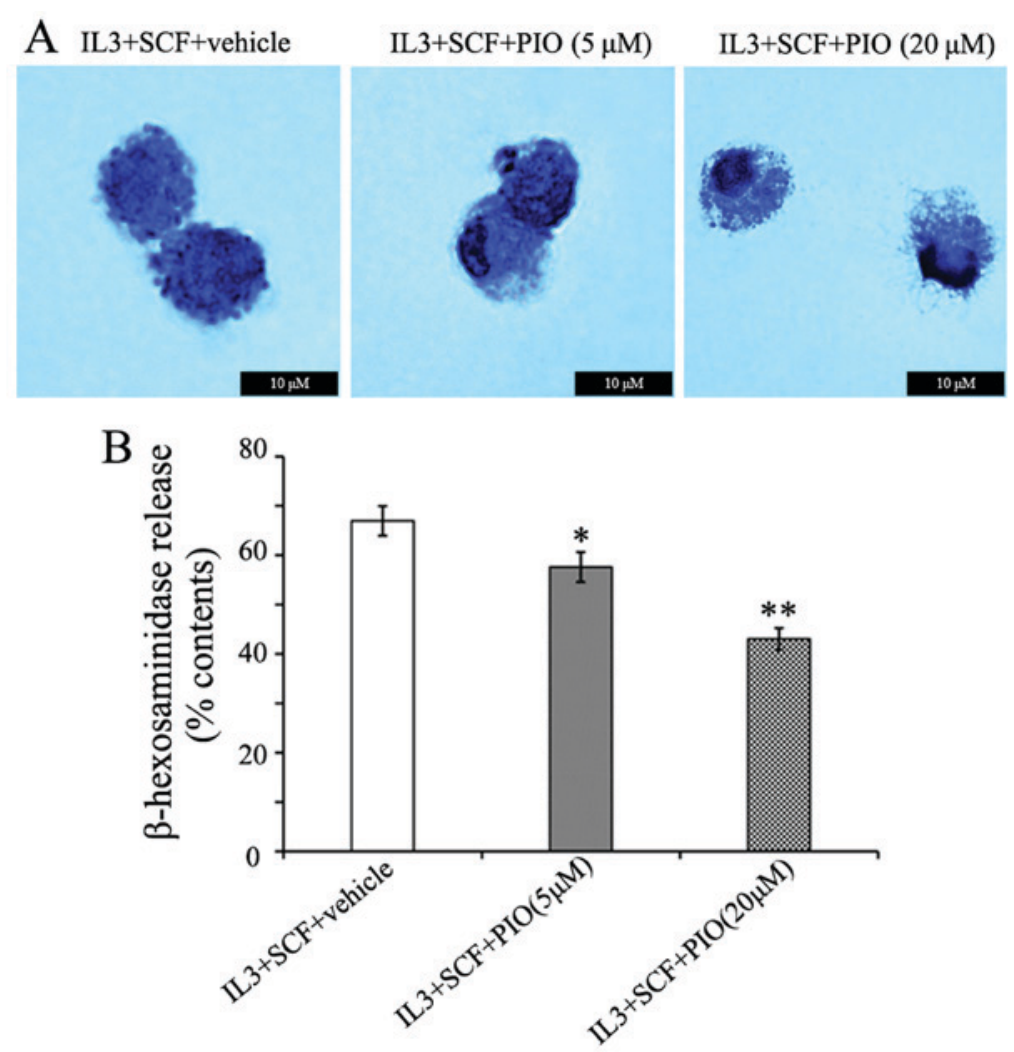

Figure 4. PIO inhibits mast cells granule formation. Bone marrow cells were cultured in IL-3 and SCF with PIO at the indicated concentrations for 4 weeks. (A) Cells were stained with toluidine blue and pictures depicted are at a magnification of $\mathrm{x} 400$. (B) Degranulation of BMMCs was detected by measuring the activity of $\beta$-hexosaminidase. The data is representative of three independent experiments. ${ }^{*} \mathrm{P}<0.05$ vs. vehicle, ${ }^{* *} \mathrm{P}<0.01$ vs. vehicle. PIO, pioglitazone; SCF, stem cell factor; BMMCs, bone marrow-derived mast cells. 

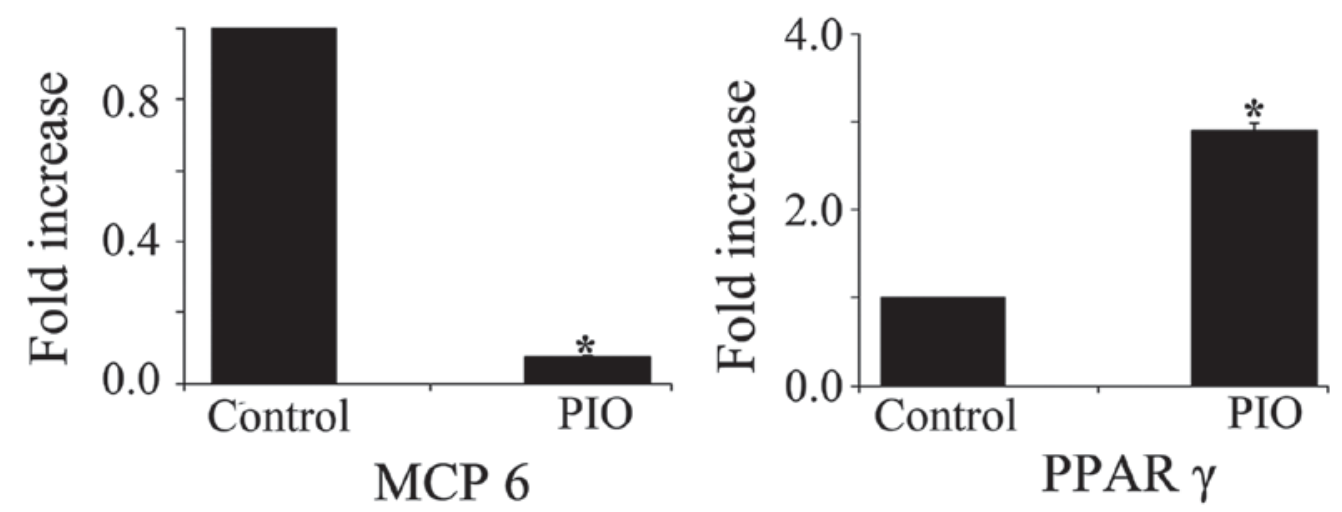

Figure 5. PIO inhibits $M C P-6$ and enhances PPAR $\gamma$ mRNA expression. Expression levels of $M C P-6$ and $P P A R \gamma$ mRNA were determined by quantitative RT-PCR analyses. The expression levels were normalized based on those of $\beta$-actin and presented as the relative expression levels. Data shown are representative of three independent experiments. ${ }^{*}<<0.01$ vs. control. PIO, pioglitazone.

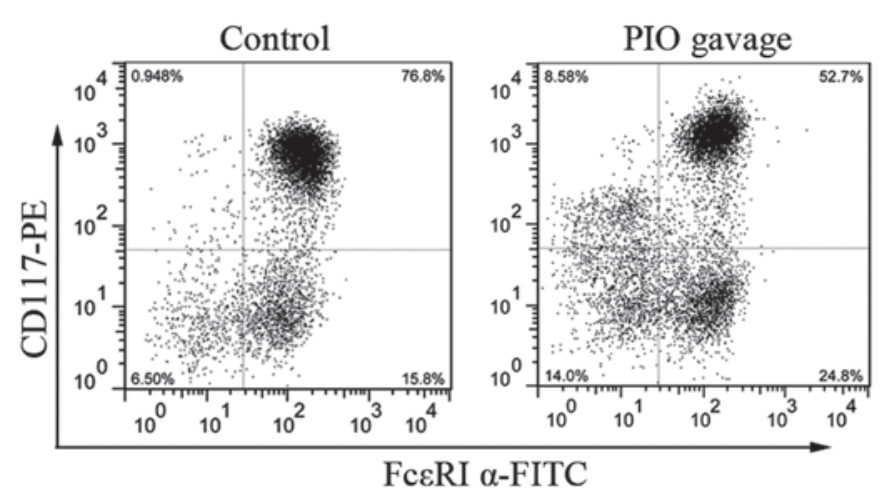

Figure 6. Systematic administration of PIO inhibits BMMCs maturation in vitro. Bone marrow cells from mice with or without PIO gavage for 7 days were cultured in IL-3 and SCF for 21 days. Expression of CD117 and FceRI $\alpha$ on the surface of BMMCs was analyzed by flow cytometry. The data is representative of three independent experiments. PIO, pioglitazone; BMMCs, bone marrow-derived mast cells; SCF, stem cell factor.

\section{Discussion}

We previously reported that PPAR $\gamma$ agonist attenuated allergic inflammation in a mouse model of allergic rhinitis (21). PIO is the effective agent in suppressing allergic inflammation. However, there are limited studies on the action mechanism of PPAR $\gamma$ in mast cells, which are the total valve of allergic diseases. In the present study, we investigated the effects of PPAR $\gamma$ agonist on mouse mast cells development. Our results show the inhibitory effects of PPAR $\gamma$ on mast cells maturation and function. More importantly, PPAR $\gamma$ agonist maintains the inhibitory effects on BMMCs in vitro.

SCF and IL-3 signaling pathways regulate mast cells development and growth. Mast cells derive from multipotential hematopoietic stem cells and their differentiation and maturation occur when they reach the target organ $(22,23)$. Mast cell progenitors leave the bone marrow, invade connective or mucosal tissue, and then proliferate and differentiate into morphologically identifiable mast cells (24). The phenotype of mast cells is determined by each site of final differentiation $(24,25)$. SCF binds its receptor, kit, which is distributed on the surface of mast cells. SCF and kit signaling is essential for the development of murine mast cells (13). Mast cells can be developed at high efficiency by culturing BMMCs in IL-3-containing media. IL-3 stimulates the proliferation of BMMCs and enhances SCF-dependent mast cells development at low cell densities (26). In the present study, we optimized the culture conditions with IL-3 (10 ng/ml) and SCF (10 ng/ml). We observed a gradual increase in mature mast cells number during the first 4 weeks of culture, especially by the end of week 2 when the percentage of CD117/FceRI $\alpha$ double-positive cells was dramatically increased to $55 \%$. After 4 weeks, bone marrow progenitors became uniform in appearance. By the end of week 6 , the percentage of CD117/FceRI $\alpha$ double-positive cells reached to $>97 \%$. The bone marrow progenitors were effectively induced into mature mast cells under IL-3 and SCF stimulation in vitro. We used this culture model for the present study.

PPAR $\gamma$ is one of the master regulators on mast cells maturation and potentially useful for therapy in various disorders involving mast cells activation (2). However, the roles of PPAR $\gamma$ in mast cells are too variable to conclude a simple regulatory mechanism of inflammation (9). Spencer et al (11), demonstrated that PIO reduced adipose tissue inflammation through reduction of mast cells number. As shown in Fig. 2, PIO greatly inhibited BMMCs maturation in a concentration-dependent manner at the indicated time points. While under certain concentration of PIO, the percentage of mature mast cells was gradually increased. After 8 weeks of culture, there was no difference in the differentiated degree between the treated and untreated BMMCs with PIO (data not shown). The results suggest that PIO inhibits early-stage mast cells maturation.

The number of mast cells in inflamed tissue can be regulated by proliferation, migration, and survival (and apoptosis) (13). The inhibitory effects of PPAR $\gamma$ on surface antigens expression and granule formation could be duo to apoptosis. In the present study, we have demonstrated that PPAR $\gamma$ agonist is able to inhibit BMMCs cells viability in a dose-dependent manner. However, Maeyama et al (9) reported the opposite result that rosiglitazone, another PPAR $\gamma$ agonist, increased cell viability of BMMCs from wide type mice. One of the possible explanations is that they obtained BMMCs with an additional 4-week culture with IL-3 alone before adding SCF. In addition, PIO acting via PPAR $\gamma$ played a proapoptotic role in murine mast cells progenitors. The result is consistent with 
our previous finding in a mouse model of allergic rhinitis (7). Our observation could suggest that PPAR $\gamma$ can modulate the expression of proapoptotic molecules in mast cells.

Each mast cell has approximately 75 granules containing a host of mediators with diverse biological roles that can be performed or formed de novo (27). Mature mast cells express mouse MCP-4, 5, 6, and 7, and contain a histamine content that is at least ten-times higher than that of immature ones (2). Histamine is involved in various physiological responses and is released from the cytoplasmic granules upon $\operatorname{IgE}$-dependent antigen stimulation (28). Histamine promotes granule maturation in mast cells and acts as a proinflammatory mediator (29). Degranulation of mast cells was decreased by PIO treatment in a dose-dependent manner, concomitant with defective granule formation. Thus, these findings highlight two possibilities: one is PIO directly inhibited granule formation of mast cells, and the other is that the decreased release of histamine affected granule maturation. MCP-6, one of mast cell-derived granule components, is secreted from mature mast cells (30). MCP-6 can activate the protease-activated receptors 1 and 2 to modulate the activities of target cells (31). It has been reported that MCP-6 is a proinflammatory mediator in various conditions (32-34). The development of airway high reactivity in a model of allergic asthma is dependent on MCP-6 (19). In our study, the expression of MCP- 6 mRNA was decreased after treatment with PIO, which is consistent with the inhibited formation of the granule by PIO. Recent studies have shown that PPAR $\gamma$ ligands suppressed antigen-induced cytokine production by MBBCs at both protein and mRNA levels $(9,10)$. As shown in the present study, PPAR $\gamma$ mRNA expression of BMMCs was increased by PIO treatment. These results suggested that PPAR $\gamma$ agonist might amplify the inhibitory effects of PPAR $\gamma$ on BMMCs by increasing PPAR $\gamma$ expression.

PPAR $\gamma$ agonist plays an inhibitory effect on mast cells maturation in vitro, which raises a possibility that PPAR $\gamma$ is involved in the physiological property of mast cell progenitors. We demonstrated our hypothesis by culturing BMMCs prepared from mice with PIO gavage. Even under the same culture condition in vitro, the percentage of CD117/FceRI $\alpha$ double-positive cells was significantly decreased in BMMCs from PIO gavage mice than that from control mice. Systemic treatment of PIO suppressed surface antigens expression of mature mast cells in vitro. Thus, PPAR $\gamma$ activation can maintain the inhibitory effects on bone marrow cells for a while in absence of PIO.

In summary, the present study has demonstrated that PPAR $\gamma$ affects mouse mast cell progenitors by inhibiting granule formation and suppressing degranulation in response to FceRI-antigen stimulation and that PPAR $\gamma$ agonist attenuates BMMCs in vitro differentiation after systemic treatment and notably increases apoptosis. Consistent with our previous in vivo studies $(7,21)$, PPAR $\gamma$ agonists might have clinical potentials for allergic disorders, such as allergic rhinitis, asthma, and atopic dermatitis.

\section{Acknowledgements}

We would like to thank Ying Lu and Bing Li (Translational medicine research center, Shanghai East Hospital, Tongji
University School of Medicine) for flow cytometry technical support and cell biology experiments.

The present study was supported by National Natural Science Foundation of China (W.W., 81300809) and Key Disciplines Group Construction Project of Pudong Health Bureau of Shanghai (PWZxq2014-09).

\section{References}

1. Kersten S, Desvergne B and Wahli W: Roles of PPARs in health and disease. Nature 405: 421-424, 2000.

2. Tachibana M, Wada K, Katayama K, Kamisaki Y, Maeyama K, Kadowaki T, Blumberg RS and Nakajima A: Activation of peroxisome proliferator-activated receptor gamma suppresses mast cell maturation involved in allergic diseases. Allergy 63: 1136-1147, 2008.

3. Zhao Y, Huang Y, He J, Li C, Deng W, Ran X and Wang D: Rosiglitazone, a peroxisome proliferator-activated receptor- $\gamma$ agonist, attenuates airway inflammation by inhibiting the proliferation of effector $\mathrm{T}$ cells in a murine model of neutrophilic asthma. Immunol Lett 157: 9-15, 2014.

4. Marcone S, Haughton K, Simpson PJ, Belton O and Fitzgerald DJ: Milk-derived bioactive peptides inhibit human endothelial-monocyte interactions via PPAR- $\gamma$ dependent regulation of NF-кB. J Inflamm (Lond) 12: 1, 2015.

5. Housley WJ, Adams CO, Vang AG, Brocke S, Nichols FC, LaCombe M, Rajan TV and Clark RB: Peroxisome proliferator-activated receptor gamma is required for $\mathrm{CD}^{+}$ T cell-mediated lymphopenia-associated autoimmunity. J Immunol 187: 4161-4169, 2011.

6. Kim SH, Hong JH and Lee YC: Ursolic acid, a potential PPAR $\gamma$ agonist, suppresses ovalbumin-induced airway inflammation and Penh by down-regulating IL-5, IL-13 and IL-17 in a mouse model of allergic asthma. Eur J Pharmacol 701: 131-143, 2013.

7. Wang W, Zhu Z, Zhu B and Ma Z: Peroxisome proliferator-activated receptor-gamma agonist induces regulatory $\mathrm{T}$ cells in a murine model of allergic rhinitis. Otolaryngol Head Neck Surg 144: 506-513, 2011.

8. Meng Y, Chen C, Tian C, Du J and Li HH: Angiotensin II-induced Egr-1 expression is suppressed by peroxisome proliferator-activated receptor- $\gamma$ ligand $15 \mathrm{~d}-\mathrm{PGJ} 2$ in macrophages. Cell Physiol Biochem 35: 689-698, 2015.

9. Maeyama K, Emi M and Tachibana M: Nuclear receptors as targets for drug development: Peroxisome proliferator-activated receptor gamma in mast cells: Its roles in proliferation and differentiation. J Pharmacol Sci 97: 190-194, 2005.

10. Sugiyama H, Nonaka T, Kishimoto T, Komoriya K, Tsuji K and Nakahata T: Peroxisome proliferator-activated receptors are expressed in mouse bone marrow-derived mast cells. FEBS Lett 467: 259-262, 2000.

11. Spencer M, Yang L, Adu A, Finlin BS, Zhu B, Shipp LR, Rasouli N, Peterson CA and Kern PA: Pioglitazone treatment reduces adipose tissue inflammation through reduction of mast cell and macrophage number and by improving vascularity. PLoS One 9: e102190, 2014.

12. Sly LM, Kalesnikoff J, Lam V, Wong D, Song C, Omeis S, Chan K, Lee CW, Siraganian RP, Rivera J and Krystal G: IgE-induced mast cell survival requires the prolonged generation of reactive oxygen species. J Immunol 181: 3850-3860, 2008.

13. Okayama Y and Kawakami T: Development, migration, and survival of mast cells. Immunol Res 34: 97-115, 2006.

14. Ma P, Mali RS, Munugalavadla V, Krishnan S, Ramdas B, Sims E, Martin H, Ghosh J, Li S, Chan RJ, et al: The PI3K pathway drives the maturation of mast cells via microphthalmia transcription factor. Blood 118: 3459-3469, 2011.

15. Wada K, Nakajima A, Katayama K, Kudo C, Shibuya A, Kubota N, Terauchi Y, Tachibana M, Miyoshi H, Kamisaki Y, et al: Peroxisome proliferator-activated receptor gamma-mediated regulation of neural stem cell proliferation and differentiation. J Biol Chem 281: 12673-12681, 2006.

16. Suzuki K and Verma IM: Phosphorylation of SNAP-23 by IkappaB kinase 2 regulates mast cell degranulation. Cell 134: 485-495, 2008.

17. Kashyap M, Bailey DP, Gomez G, Rivera J, Huff TF and Ryan JJ: TGF-beta1 inhibits late-stage mast cell maturation. Exp Hematol 33: 1281-1291, 2005. 
18. Lantz CS and Huff TF: Murine $\mathrm{KIT}^{+}$lineage- bone marrow progenitors express Fc gamma-RII but do not express $\mathrm{Fc}$ epsilon-RI until mast cell granule formation. J Immunol 154 355-362, 1995.

19. Cui Y, Dahlin JS, Feinstein R, Bankova LG, Xing W, Shin K, Gurish MF and Hallgren J: Mouse mast cell protease- 6 and MHC are involved in the development of experimental asthma. J Immunol 193: 4783-4789, 2014.

20. Vangansewinkel T, Geurts N, Quanten K, Nelissen S, Lemmens S, Geboes L, Dooley D, Vidal PM, Pejler G and Hendrix S: Mast cells promote scar remodeling and functional recovery after spinal cord injury via mouse mast cell protease 6. FASEB J 30 2040-2057, 2016

21. Wang W, Zhu Z, Zhu B and Ma Z: Pioglitazone attenuates allergic inflammation and induces production of regulatory $\mathrm{T}$ lymphocytes. Am J Rhinol Allergy 24: 454-458, 2010.

22. Gurish MF and Austen KF: Developmental origin and functional specialization of mast cell subsets. Immunity 37: 25-33, 2012.

23. Rao KN and Brown MA: Mast cells: Multifaceted immune cells with diverse roles in health and disease. Ann N Y Acad Sci 1143 83-104, 2008.

24. Chen CC, Grimbaldeston MA, Tsai M, Weissman IL and Galli SJ: Identification of mast cell progenitors in adult mice. Proc Natl Acad Sci USA 102: 11408-11413, 2005.

25. Kitamura Y, Oboki K and Ito A: Molecular mechanisms of mast cell development. Immunol Allergy Clin North Am 26: 387-405; v, 2006.

26. Saito H: Culture of human mast cells from hemopoietic progenitors. Methods Mol Biol 315: 113-122, 2006.

27. Succar J, Douaiher J, Lancerotto L, Li Q, Yamaguchi R, Younan G, Pejler G and Orgill DP: The role of mouse mast cell proteases in the proliferative phase of wound healing in microdeformational wound therapy. Plast Reconstr Surg 134: 459-467, 2014.
28. Metcalfe DD, Baram D and Mekori YA: Mast cells. Physiol Rev 77: 1033-1079, 1997.

29. Nakazawa S, Sakanaka M, Furuta K, Natsuhara M, Takano H, Tsuchiya S, Okuno Y, Ohtsu H, Nishibori M, Thurmond RL, et al: Histamine synthesis is required for granule maturation in murine mast cells. Eur J Immunol 44: 204-214, 2014.

30. Hirai S, Ohyane C, Kim YI, Lin S, Goto T, Takahashi N, Kim CS, Kang J, Yu R and Kawada T: Involvement of mast cells in adipose tissue fibrosis. Am J Physiol Endocrinol Metab 306: E247-E255, 2014.

31. Liu ZQ, Song JP, Liu X, Jiang J, Chen X, Yang L, Hu T, Zheng PY, Liu ZG and Yang PC: Mast cell-derived serine proteinase regulates T helper 2 polarization. Sci Rep 4: 4649, 2014.

32. McNeil HP, Shin K, Campbell IK, Wicks IP, Adachi R, Lee DM and Stevens RL: The mouse mast cell-restricted tetramer-forming tryptases mouse mast cell protease 6 and mouse mast cell protease 7 are critical mediators in inflammatory arthritis. Arthritis Rheum 58: 2338-2346, 2008.

33. Shin K, Nigrovic PA, Crish J, Boilard E, McNeil HP, Larabee KS, Adachi R, Gurish MF, Gobezie R, Stevens RL and Lee DM: Mast cells contribute to autoimmune inflammatory arthritis via their tryptase/heparin complexes. J Immunol 182: 647-656, 2009.

34. Hamilton MJ, Sinnamon MJ, Lyng GD, Glickman JN, Wang X, Xing W, Krilis SA, Blumberg RS, Adachi R, Lee DM and Stevens RL: Essential role for mast cell tryptase in acute experimental colitis. Proc Natl Acad Sci USA 108: 290-295, 2011. 